\title{
A Mathematical Programming Approach to Brand Efficiency of Smartphones in the US Market
}

\author{
Shiu-Wan Hung, ${ }^{1}$ Han-Chung Chou, ${ }^{1,2}$ Wen-Min Lu, ${ }^{2}$ and Shi-Xiao Wang ${ }^{1}$ \\ ${ }^{1}$ Department of Business Administration, National Central University, No. 300, Jung-Da Road, Jung-Li City, Taoyuan 320, Taiwan \\ ${ }^{2}$ Department of Financial Management, National Defense University, No. 70, Sec. 2, Zhongyang North Rd., Beitou, Taipei 112, Taiwan \\ Correspondence should be addressed to Wen-Min Lu; wenmin.lu@gmail.com
}

Received 31 March 2017; Revised 7 June 2017; Accepted 19 July 2017; Published 23 August 2017

Academic Editor: Mauro Gaggero

Copyright (c) 2017 Shiu-Wan Hung et al. This is an open access article distributed under the Creative Commons Attribution License, which permits unrestricted use, distribution, and reproduction in any medium, provided the original work is properly cited.

\begin{abstract}
This study applied mathematical programming approach to investigate the brand efficiency of smartphone brands by collecting data of 2013-2015 from Consumer Report. The brand efficiency was completed by employing the slack-based measure in data envelopment analysis. The degree of inefficiency of each brand was evaluated, and each brand's metatechnology ratio was calculated using the metafrontier concept. The results revealed that the sampled smartphone brands reach the highest average brand efficiency in 2013, where Apple exhibited the highest brand efficiency among the sampled brands. The high brand efficiency in 2013 was attributed to the small number of product types at beginning of the growth period of smartphones. Finally, this study examined the efficiency of smartphone brands among four major telecommunications operators in the United States. It was found that Apple demonstrated the highest efficiency with all four operators, while no significant difference was noted among operators and smartphone brands.
\end{abstract}

\section{Introduction}

According to the report by TrendForce (http://press.trendforce.com.tw/node/view/3063.html), a world-leading market intelligence provider, a total of 1.293 billion smartphones were sold globally in 2015 , showing an annual growth rate of $10.3 \%$. However, with the increase in the prevalence of smartphones and high-speed Internet services, competition between smartphone manufacturers has become increasingly fierce. In response to the market demand, the functionality of smartphones increases as well. In addition to the primary functions such as calling and texting, gaming and entertainment, social media and Internet browsing, time checking, and camera shooting, the global positioning system and micropayment have also become important features of contemporary smartphones. Furthermore, smartphone manufacturers are currently developing virtual reality capability for their products.

Pandey and Nakra [1] proposed that, with the widespread innovations in the communication technology, people shift from their basic phones to the smartphones that can function similar to personal computers (PCs). The high portability, high penetration rate, and short life cycles contribute to the strong competition between smartphone manufacturers. The initial focus of competition on specifications has shifted to the current focus on both price and specifications. The price and performance have in turn become the main concerns of consumers. Consumers typically prefer high-performance smartphones and they are concerned about obtaining and assessing performance information regarding smartphone's characteristic. They also assess the price efficiency of smartphones [2]. Lancaster [3] argued that goods are a combination of various characteristics. Rosen [4] proposed the hedonic price theory, which posits that consumers can determine the implicit price of products when they review their characteristics and performance. When little is known about these factors, consumers typically determine the quality of goods according to the price.

Liu and Liang [5] showed that $71 \%$ of the subjects are willing to spend more money to buy their favorite brands of smartphones, and they suggested that the brand logo is the most important criterion when consumers make a decision 
to buy a product. Consumers frequently perceive price as a crucial performance indicator. In other words, consumers generally have positive expectations about a product because of their trust in the price [6]. They also believe that high prices indicate high performance. Because vendors and consumers often have asymmetric information, smartphone prices may not really reflect their functional performance [7]. A competitive market with perfect information is characterized by efficient brands. Improving consumer access to product and brand information is an effective approach to eliminating market inefficiencies [2]. Therefore, assessment of smartphone efficiency for the prices and functions of different brands is an important issue.

To compare brand efficiency across multiple smartphone brands, a common metafrontier was defined as the boundary of an unrestricted technology set. Group frontiers were also defined as the boundaries of restricted technology sets, with restrictions derived from a lack of economic infrastructure or other characteristics of the production environment. Importantly, the metafrontier envelops the group frontiers (thus, the metafrontier is related to the concept of the metaproduction function defined by Hayami and Ruttan (1971): "the metaproduction function can be regarded as the envelope of commonly conceived neoclassical production functions" (p. 82)). Thus, efficiencies measured relative to the metafrontier can be decomposed into two components: one that measures the distance from an input-output point to the group frontier and the other that measures the distance between the group frontier and the metafrontier.

To determine brand efficiency, this study first employed data envelopment analysis (DEA) [8], which involved evaluating the variance in brand efficiency among different products of the same brand. In contrast to other methods, DEA enables a detailed interpretation of brand inefficiency and an examination of how to alleviate the inefficiency. The changes in brand efficiency in the smartphone industry were analyzed on the basis of product price and performance. Subsequently, improvement strategies were developed to provide a reference for smartphone manufacturers and consumers.

The objectives of this study are listed as follows. First, this study compares the function performance in different smartphone brands and explores their strengths and weakness. The second objective is to evaluate the brand efficiency of smartphone by using the mathematical programming approach in DEA. The relationship between smartphone brand efficiency and telecommunication operators was also explored. Finally, the metafrontier concept firstly was employed to measure the technology gap ratio of various smartphone manufacturers and provide a reference for decision makers.

The remainder of this paper is organized as follows. Section 2 reviews the literature on market efficiency in the context of price dispersion in marketplaces. Section 3 describes the research design of the slack-based measure (SBM) metafrontier methodology and introduces the criteria and descriptions of the sample data. The results of empirical analysis are provided in Section 4. Finally, Section 5 summarizes our conclusions, discusses limitations, and provides guidance for future research.

\section{Literature Review}

Tellis and Wernerfelt [9] firstly completed an integrated study on price and quality based on literature reviews. They selected 1,271 observations of 105 product categories in a data sample from 1939 to 1980 (compiled by Consumer Reports), including the correlation coefficients between price and quality from 1,365 product markets. The results revealed a weak correlation between price and quality (mean correlation coefficient $=$ .27). Kamakura et al. [2] presented a methodology for measuring the inefficiency of each brand within a product category. They used their estimates to test hypotheses about the variations in efficiency across product categories and find that lower priced categories appeared to be more inefficient.

Chaudhuri and Holbrook [10] examined two aspects of brand loyalty, namely, purchased loyalty and attitudinal loyalty, as linking variables in the chain of effects from brand trust and brand affect to brand performance (market share and relative price). When the product- and brand-level variables are considered as control factors, the combination of brand trust and brand affect determines the purchase loyalty and attitudinal loyalty. Higher purchase loyalty leads to greater market share, and higher attitudinal loyalty results in a higher relative price for the brand. Liu and Liang [5] investigated the four top-selling smartphone vendors based on International Data Corporation (IDC) statistics (IDC Worldwide Mobile Phone Tracker, 2012) and found that $71 \%$ of the subjects are willing to spend more money to buy their favorite brand.

Jiang and Balasubramanian [11] argued that the market efficiency of traditional retail formats has been questioned in studies of the price-quality relationship. Both price efficiency and market efficiency were used to investigate the relationships between price and quality. The results suggested that the online marketplace is not more efficient than traditional retail settings.

Lee et al. [12] analyzed the platforms used by content providers by using a metafrontier analysis to compare the efficiencies of different groups in identical industries. The results illustrated that groups focusing on the iOS platform achieved a high average efficiency with low variance within the group, because the iOS platform manages the content novelty and uncertainty risk in the selection process.

Because of the growth and competition in the smartphone industry, Yeh et al. [13] explained the motivation for consumers' loyalty to smartphone brands, by testing data collected from 157 respondents against the research model using a PLS. Their results showed that age enhances the emotional value-brand loyalty and social value-brand loyalty relationships but weakens the brand identification-brand loyalty relationship. Gender does not play a moderating role in the determination of smartphone brand loyalty. Their study provided several important theoretical and practical implications for smartphone brand management.

To summarize, this study offers several important information including the following. Firstly, this study extends prior research to explore the function performance in different smartphone brands and to analyze their strengths and weakness. Secondly, this is the first study to use the 
TABLE 1: Input and output definitions.

\begin{tabular}{|c|c|c|}
\hline & Variable & Definition \\
\hline Input & Price & $\begin{array}{l}\text { The product purchase price. The buyer owns the product after purchase, and the ownership is } \\
\text { transferred from the seller to the buyer }\end{array}$ \\
\hline \multirow{10}{*}{ Output } & Ease of use (Q1) & How easy is it is to access the phone's various features and modes \\
\hline & Messaging (Q2) & $\begin{array}{c}\text { Assessing keyboard ergonomics, e-mail readability, attachment capabilities, and text-messaging } \\
\text { features }\end{array}$ \\
\hline & Web browsing (Q3) & Assess browser capabilities \\
\hline & Display quality (Q4) & $\begin{array}{l}\text { Representing overall picture quality, including pixel resolution, contrast under normal and bright } \\
\text { lighting (outdoor use) conditions, and color accuracy }\end{array}$ \\
\hline & Voice quality (Q5) & Incorporating listening and talking in noisy and quiet settings while on a phone call \\
\hline & Phoning (Q6) & $\begin{array}{l}\text { Considering the step-saving functions for making and receiving calls, including hands-free } \\
\text { capabilities such as voice command and Bluetooth, speed dialing, ringer controls, call timers, and } \\
\text { more. We also evaluated keypad readability under different lighting conditions }\end{array}$ \\
\hline & Battery life (Q7) & $\begin{array}{l}\text { Representing tests under nominal cell-network signals, including battery consumption while } \\
\text { performing tasks that involve voice, data, display, and other factors }\end{array}$ \\
\hline & Camera image quality (Q8) & Evaluating resolution, dynamic range, color accuracy, and visual noise \\
\hline & Camera video quality (Q9) & Judging recorded video images shot at the highest quality setting available \\
\hline & Portability (Q10) & Representing our judgment based on the ideal combination of size and weight \\
\hline
\end{tabular}

mathematical programming approach to evaluate the brand efficiency of smartphone in the metafrontier concept.

\section{Research Design}

3.1. Data Collection. Consumer Reports (the Consumer Reports Survey Research Department, a team of highly trained social scientists, surveys millions of consumers each year using state-of-the-art techniques; collecting feedback on a broad range of real-world experiences with products, services) is open and credible. Therefore, most scholars use this Consumer Reports for marketing research [11]. Table 1 lists the definitions of the price and function characteristics from Consumer Reports. A total of 200 smartphoneyear observations were collected for the 2013-2015 period. To acquire complete product data, this study selected the following eight smartphone brands for investigation: Apple, BlackBerry, HTC, LG, Motorola, Nokia, Samsung, and Sony. Table 2 lists the brands and model numbers of the smartphones, while Table 3 shows the descriptive statistics for the quality indicators of the smartphones. The mean score of the outputs of the most expensive smartphones was approximately 5, whereas that of the lowest-priced smartphones was less than 3 . These results match with consumers' intuitive reactions, in which high-priced smartphones represent high quality and performance and low-priced smartphones tend to be inconsistent in quality. However, data from the Consumer Reports do not reveal the brand efficiency. Therefore, we further investigated whether brand efficiency is utilized by smartphone manufacturers.

3.2. Determine Input and Output Variables. A smartphone brand is defined as efficient if it provides the highest value per dollar spent for that set of function characteristics within a smartphone category. Since a smartphone's efficiency is a complex phenomenon that cannot be characterized by just a single criterion, a number of studies have argued that a multifactor performance measurement model may be used [14]. To measure a smartphone brand efficiency, this study investigated the price-function characteristics relationship. Subsequently, a metafrontier analysis was conducted to assess the technology gaps among these smartphone brands. Table 4 illustrates the Pearson correlation analysis results for the inputs and outputs. Observations of negative correlations between inputs and outputs flaws DEA logic and therefore any results under these conditions are highly suspect. To preserve the isotone property for outputs, the data must be rescaled to remove the negative correlation. Therefore, voice quality (Q5), phoning (Q6), and portability (Q10) were excluded in the DEA model.

3.3. SBM Metafrontier Approach. According to Battese and Rao [15], a metafrontier is defined as the boundary of a production possibility set of all input-output combinations, whereas group frontiers are conceptualized as the subboundaries of production possibility sets of groups of firms. A metafrontier always envelops the corresponding group frontiers. The metafrontier concept is illustrated in Figure 1.

Figure 1 contains three group-specific production possibility sets, namely, $11^{\prime}, 22^{\prime}$, and $33^{\prime}$, which are referred to as group frontiers. In this case, the universe of firms is divided into $K(k=1,2,3)$ groups. The convex frontier $M M^{\prime}$ may be the metafrontier that envelops the three group frontiers. First, technical efficiency is measured relative to the group$k$ frontier. For example, the technical efficiency of Decision Making Unit (DMU) $G_{1}$ is calculated as $0 G_{1} / 0 G_{2}$ in $22^{\prime}$ frontier. Meanwhile, $0 G_{1} / 0 F$ represents the metaefficiency, which can be decomposed into within-group efficiency $\left(0 G_{1} / 0 G_{2}\right)$ and the metatechnology ratio (DEA-MTR) or technological gap $\left(0 G_{2} / 0 F\right)[15,16]$. The mathematical formulation of the 
TABLE 2: Smartphone brands and models.

\begin{tabular}{|c|c|c|}
\hline Brand & Year & Model \\
\hline \multirow{3}{*}{ Apple } & 2013 & iPhone 4S, iPhone 4, and iPhone 3GS \\
\hline & 2014 & iPhone 5, iPhone 4S, and iPhone 4 \\
\hline & 2015 & iPhone 5S, iPhone 5C, and iPhone $4 \mathrm{~S}$ \\
\hline \multirow{3}{*}{ BlackBerry } & 2013 & Torch 9810, Torch 9850, Bold 9900 4G, Bold 9780, and Bold 9930 \\
\hline & 2014 & Z10, Q10, Torch 9810, and Bold \\
\hline & 2015 & Z10, Q10, Z30, and Bold 9930 \\
\hline \multirow{3}{*}{ HTC } & 2013 & One X, Vivid, Titan 2, Evo 4G LTE, Arrive, One S, Amaze 4G, My Touch 4G Slide, Radar 4G, and Trophy \\
\hline & 2014 & $\begin{array}{c}\text { One, One X+, One VX, Windows Phone 8X, Windows First, Evo 4G LTE, 8XT, Driod DNA, and Windows } \\
\text { Phone }\end{array}$ \\
\hline & 2015 & One M8, One, One max, 8XT, One Remix, and Windows Phone 8X \\
\hline \multirow{3}{*}{ LG } & 2013 & Nitro HD, Viper, Optimus Elite, Spectrum, and Lucid \\
\hline & 2014 & $\begin{array}{c}\text { Optimus G, Optimus G Pro, Optimus G, Optimus F3, Viper, Optimus Elite, Optimus L9, Spectrum 2, Lucid 2, } \\
\text { and Intuition }\end{array}$ \\
\hline & 2015 & G3, G2, G Pro, G Flex, Viper, Optimus L90, and Optimus F3Q \\
\hline \multirow{3}{*}{ Motorola } & 2013 & Atrix 2, XPRT, Droid Razr Maxx, Droid Razr, and Droid 4 \\
\hline & 2014 & Photon Q 4G LTE, Droid Razr Maxx HD, Droid Razr HD, Droid Razr M, and Droid 4 \\
\hline & 2015 & Moto X, Droid Maxx, Droid Mini, Moto X, and Droid Razr M \\
\hline \multirow{3}{*}{ Nokia } & 2013 & Lumia 900 \\
\hline & 2014 & Lumia, Lumia 920, Lumia 925, Lumia 521, Lumia 928, and Lumia 822 \\
\hline & 2015 & Lumia 1020, Lumia 1520, Lumia 925, Lumia 635, Lumia Icon, and Lumia 928 \\
\hline \multirow{3}{*}{ Samsung } & 2013 & $\begin{array}{c}\text { Galaxy S 3, Galaxy S } 2 \text { Skyrocket, Galaxy Note, Galaxy S 2, Galaxy Exhilarate, Focus 2, Rugby Smart, Galaxy S2 } \\
\text { Epic 4G Touch, Epic 4G, Conquer 4G, Replenish, Galaxy Blaze 4G, Galaxy Nexus, Srtatosphere, and Droid } \\
\text { Charge }\end{array}$ \\
\hline & 2014 & $\begin{array}{c}\text { Galaxy S4, Galaxy S4 Active, Galaxy S3, Galaxy Note 2, Galaxy Rugby Pro, Galaxy Victory 4G LTE, Galaxy S2, } \\
\text { Galaxy Exhibit, ATIV Odyssey, Galaxy Stellar, and Galaxy Stratosphere } 2\end{array}$ \\
\hline & 2015 & $\begin{array}{l}\text { Galaxy S5, Galaxy S5 Active, Galaxy S4, Galaxy S4 Active, Galaxy Note 3, Galaxy S3, Galaxy S4 Mini, Galaxy } \\
\text { Mega, Galaxy Rugby Pro, Galaxy S4 Zoom, Galaxy S5 Sport, ATIV S Neo, and ATIV SE }\end{array}$ \\
\hline \multirow{3}{*}{ Sony } & 2013 & Xperia ion and Xperia Play \\
\hline & 2014 & Xperia $\mathrm{Z}$ \\
\hline & 2015 & Xperia Z1S \\
\hline
\end{tabular}

TABLE 3: Descriptive statistics ( $n=200$ smartphone-year observations).

\begin{tabular}{|c|c|c|c|c|c|c|c|c|c|c|c|}
\hline \multirow{2}{*}{\multicolumn{2}{|c|}{$\begin{array}{r}\text { Input } \\
\text { Price } \\
\end{array}$}} & \multicolumn{10}{|c|}{ Output } \\
\hline & & Q1 & Q2 & Q3 & Q4 & Q5 & Q6 & Q7 & Q8 & Q9 & Q10 \\
\hline Max. & 800 & 5 & 5 & 5 & 5 & 3 & 5 & 5 & 5 & 4 & 5 \\
\hline Min. & 500 & 3 & 4 & 2 & 3 & 2 & 2 & 2 & 1 & 1 & 1 \\
\hline Average & 587.75 & 4.73 & 4.63 & 4.54 & 4.67 & 2.81 & 4.05 & 3.63 & 3.47 & 2.98 & 3.90 \\
\hline SD & 86.11 & 0.48 & 0.48 & 0.72 & 0.54 & 0.39 & 0.56 & 0.75 & 0.80 & 0.69 & 0.86 \\
\hline
\end{tabular}

Note. Q1 = ease of use, Q2 = messaging, Q3 = web browsing, Q4 = display quality, Q5 = voice quality, Q6 = phoning, Q7 = battery life, Q8 = camera image quality, Q9 = camera video quality, and Q10 = portability.

metafrontier is $0 G_{1} / 0 F=0 G_{1} / 0 G_{2} \times 0 G_{2} / 0 F$. Specifically, the group frontier (within-group efficiency) measures the technical efficiency of a DMU under a group, whereas the DEA-MTR measures the distance between the group frontier and metafrontier (technological gap).

As explained by Cooper et al. [17], DEA models can be categorized into two forms. The first one consists of nonradial models, such as the additive model [18], the Russell measure [19], the range-adjusted measure [20], and the SBM model [21]. The second form includes radial models, such as the Charnes-Cooper-Rhodes (CCR) model proposed by Charnes et al. [8] and the Banker-Charnes-Cooper (BCC) model proposed by Banker et al. [22]. This study adopted the SBM model to investigate smartphone brand efficiency. The SBM model owns the following desirable features, which make it suitable for investigating the efficiency of the process 
TABLE 4: Pearson's correlations for inputs and outputs.

\begin{tabular}{|c|c|c|c|c|c|c|c|c|c|c|c|}
\hline & Price & Q1 & Q2 & Q3 & Q4 & Q5 & Q6 & Q7 & Q8 & Q9 & Q10 \\
\hline \multirow{2}{*}{ Price } & 1.0000 & & & & & & & & & & \\
\hline & $p=-$ & & & & & & & & & & \\
\hline \multirow{2}{*}{ Q1 } & .0303 & 1.0000 & & & & & & & & & \\
\hline & $p=.670$ & $p=-$ & & & & & & & & & \\
\hline \multirow{2}{*}{ Q2 } & $.1609^{*}$ & $.2763^{*}$ & 1.0000 & & & & & & & & \\
\hline & $p=.023$ & $p=.000$ & $p=-$ & & & & & & & & \\
\hline \multirow{2}{*}{ Q3 } & $.1389^{*}$ & $.3666^{*}$ & $.6670^{*}$ & 1.0000 & & & & & & & \\
\hline & $p=.050$ & $p=.000$ & $p=0.00$ & $p=-$ & & & & & & & \\
\hline \multirow{2}{*}{ Q4 } & $.2132^{*}$ & $.2563^{*}$ & $.1771^{*}$ & .2013 & 1.0000 & & & & & & \\
\hline & $p=.002$ & $p=.000$ & $p=.012$ & $p=.004^{*}$ & $p=-$ & & & & & & \\
\hline \multirow{2}{*}{ Q5 } & -.0571 & .1000 & -.0856 & .0269 & .0345 & 1.0000 & & & & & \\
\hline & $p=.422$ & $p=.159$ & $p=.228$ & $p=.705$ & $p=.628$ & $p=-$ & & & & & \\
\hline \multirow{2}{*}{ Q6 } & -.0519 & $.3832^{*}$ & .0808 & .1259 & $.0823^{*}$ & .0162 & 1.0000 & & & & \\
\hline & $p=.466$ & $p=.000$ & $p=.256$ & $p=.076$ & $p=.246$ & $p=.820$ & $p=-$ & & & & \\
\hline \multirow{2}{*}{ Q7 } & $.1535^{*}$ & -.0836 & $.3200^{*}$ & $.3143^{*}$ & .0319 & $.1518^{*}$ & -.1152 & 1.0000 & & & \\
\hline & $p=.030$ & $p=.239$ & $p=.000$ & $p=.000$ & $p=.654$ & $p=.032$ & $p=.104$ & $p=-$ & & & \\
\hline \multirow{2}{*}{ Q8 } & $.3081^{*}$ & $.2150^{*}$ & $.1970^{*}$ & $.3409^{*}$ & $.3712^{*}$ & $.2369^{*}$ & .0533 & .3066 & 1.0000 & & \\
\hline & $p=.000$ & $p=.002$ & $p=.005$ & $p=.000$ & $p=.000$ & $p=.001$ & $p=.453$ & $p=.000$ & $p=-$ & & \\
\hline \multirow{2}{*}{ Q9 } & $.2334^{*}$ & $.2384^{*}$ & -.0881 & .0071 & $.3949^{*}$ & $.1860^{*}$ & -.0749 & .0595 & $.4935^{*}$ & 1.0000 & \\
\hline & $p=.001$ & $p=.001$ & $p=.215$ & $p=.921$ & $p=.000$ & $p=.008$ & $p=.292$ & $p=.403$ & $p=.000$ & $p=-$ & \\
\hline \multirow{2}{*}{ Q10 } & -.1358 & $.2473^{*}$ & $-.4415^{*}$ & $-.3515^{*}$ & $.1619^{*}$ & .0593 & $.4554^{*}$ & $-.3072^{*}$ & -.0517 & .1302 & 1.0000 \\
\hline & $p=.055$ & $p=.000$ & $p=.000$ & $p=.000$ & $p=.022$ & $p=.405$ & $p=.000$ & $p=.000$ & $p=.467$ & $p=.066$ & $p=-$ \\
\hline
\end{tabular}

Note 1. Q1 = ease of use, Q2 = messaging, Q3 = web browsing, Q4 = display quality, Q5 = voice quality, Q6 = phoning, Q7 = battery life, Q8 = camera image quality, Q9 = camera video quality, and Q10 = portability. Note 2. Single asterisks $(*)$ denote significant level at 0.05 .

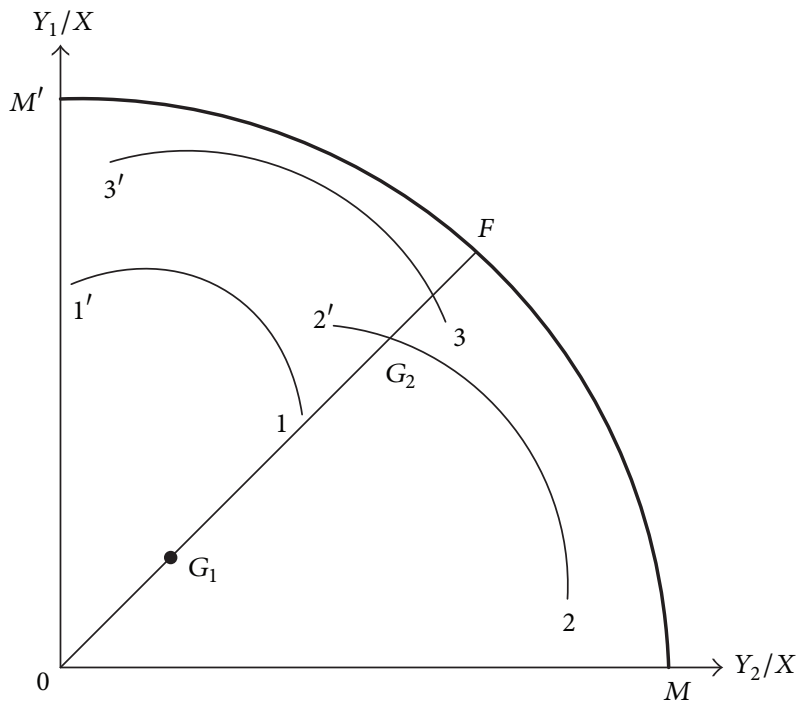

FIGURE 1: Technical efficiencies and the metafrontier.

of converting multiple inputs into multiple outputs: (a) he model is monotonically decreasing and unit invariant relative to inputs and outputs; (b) the model deals directly with the output shortfalls and input excesses; (c) the measure is determined by consulting only a reference set of DMUs and is not affected by statistics encompassing the whole data set.
The no-oriented SBM model evaluates the metaefficiency of the target $\mathrm{DMU}_{o}(o=1, \ldots, n)$ by solving the following mathematical programming approach:

$$
\begin{aligned}
\operatorname{Min} \quad \eta_{o} & =\frac{\left(1-(1 / m) \sum_{i=1}^{m}\left(s_{i}^{-} / x_{i o}\right)\right)}{\left(1+(1 / s) \sum_{r=1}^{s}\left(s_{r}^{+} / y_{r o}\right)\right)} \\
\text { s.t. } \quad x_{i o} & =\sum_{j=1}^{n} x_{i j} \lambda_{j}+s_{i}^{-}, \quad i=1, \ldots, m, \\
y_{r o} & =\sum_{j=1}^{n} y_{r j} \lambda_{j}-s_{r}^{+}, \quad r=1, \ldots, s, \\
\sum_{j=1}^{n} \lambda_{j} & =1, \\
& \lambda_{j} \geq 0, \quad s_{i}^{-} \geq 0, s_{r}^{+} \geq 0,
\end{aligned}
$$

where $n$ is the number of DMUs; $x_{i j}>0$ and $y_{r j}>0$ are the levels of the $i$ th input and $r$ th output, respectively, at the $j$ th DMU; and $\lambda_{j}$ is the weight of the $j$ th DMU. Here, the target DMU is the DMU under evaluation. Equation (1) specifies that the sum of the weights must be equal to 1 . This suggests that the constructed optimal practice frontier exhibits variable returns-to-scale (VRS) technology. Hence, the efficiency score obtained from (1) reflects the ability of management to transform inputs to produce outputs. The term $\eta_{o}$ is the technical efficiency relative to the metafrontier 
(DEA-MF). A DMU is regarded as SBM-efficient if and only if $\eta_{o}^{*}=1$.

Equation (1) can be transformed into a linear program by introducing a positive scalar variable $t$ [23].

$$
\begin{array}{ll}
\text { Min } \quad \tau_{o} & =t-\frac{1}{m} \sum_{i=1}^{m} \frac{t s_{i}^{-}}{x_{i o}} \\
\text { s.t. } & 1=t+\frac{1}{s} \sum_{r=1}^{s} \frac{t s_{r}^{+}}{y_{r o}} \\
x_{i o} & =\sum_{j=1}^{n} x_{i j} \lambda_{j}+s_{i}^{-}, \quad i=1, \ldots, m, \\
y_{r o} & =\sum_{j=1}^{n} y_{r j} \lambda_{j}-s_{r}^{+}, \quad r=1, \ldots, s, \\
\sum_{j=1}^{n} \lambda_{j} & =1,
\end{array}
$$

$$
\lambda_{j} \geq 0, s_{i}^{-} \geq 0, s_{r}^{+} \geq 0, t>0 .
$$

Now, let us define

$$
\begin{gathered}
S_{i}^{-}=t s_{i}^{-}, \\
S_{r}^{+}=t s_{r}^{+}, \\
\Gamma=t \lambda_{j} .
\end{gathered}
$$

Then, (2) becomes the following linear program $t, S_{i}^{-}, S_{r}^{+}$, and $\Gamma$ :

$$
\begin{aligned}
& \text { Min } \tau_{o}=t-\frac{1}{m} \sum_{i=1}^{m} \frac{S_{i}^{-}}{x_{i o}} \\
& \text { s.t. } \quad 1=t+\frac{1}{s} \sum_{r=1}^{s} \frac{S_{r}^{+}}{y_{r o}} \\
& t x_{i o}=\sum_{j=1}^{n} x_{i j} \Gamma_{j}+S_{i}^{-}, \quad i=1, \ldots, m, \\
& t y_{r o}=\sum_{j=1}^{n} y_{r j} \Gamma_{j}-S_{r}^{+}, \quad r=1, \ldots, s, \\
& \sum_{j=1}^{n} \Gamma_{j}=t, \quad \Gamma_{j} \geq 0, S_{i}^{-} \geq 0, S_{r}^{+} \geq 0, t>0 .
\end{aligned}
$$

Note that $t>0$ because of the first constraint, meaning that the transformation is reversible. Thus, let an optimal solution of (4) be

$$
\left(\tau_{o}^{*}, t^{*}, \Gamma^{*}, S_{i}^{-*}, S_{r}^{+*}\right)
$$

Then, an optimal solution of (1) is given by

$$
\begin{gathered}
\eta_{o}^{*}=\tau_{o}^{*}, \\
\lambda_{j}^{*}=\frac{\Gamma_{j}^{*}}{t^{*}}, \\
s_{i}^{-*}=\frac{S_{i}^{-*}}{t^{*}}, \\
s_{r}^{+*}=\frac{S_{r}^{+*}}{t^{*}} .
\end{gathered}
$$

Next, we estimate the group frontiers through SBM DEA. Assume there are $n$ DMUs in $k$ groups $(k=1, \ldots, K)$; then, the VRS nonoriented SBM DEA fractional program is as follows:

$$
\operatorname{Min} \theta_{o}^{k}=\frac{\left(1-(1 / m) \sum_{i=1}^{m}\left(s_{i}^{k-} / x_{i o}^{k}\right)\right)}{\left(1+(1 / s) \sum_{r=1}^{s}\left(s_{r}^{k+} / y_{r o}^{k}\right)\right)}, \begin{aligned}
& \\
& \quad k=1, \ldots, K
\end{aligned}
$$$$
\text { s.t. } \quad x_{i o}^{k}=\sum_{j=1}^{n_{k}} x_{i j}^{k} \lambda_{j}^{k}+s_{i}^{k-}, \quad i=1, \ldots, m,
$$$$
\begin{aligned}
& y_{r o}^{k}=\sum_{j=1}^{n_{k}} y_{r j}^{k} \lambda_{j}^{k}-s_{r}^{k+}, \quad r=1, \ldots, s, \\
& \sum_{j=1}^{n_{k}} \lambda_{j}^{k}=1,
\end{aligned}
$$

$$
\lambda_{j}^{k} \geq 0, s_{i}^{k-} \geq 0, s_{r}^{k+} \geq 0,
$$

where the superscript $k$ denotes the group frontier. The value of $\theta_{o}^{k}$ that solves the fractional program defined by (7) shows the technical efficiency of $\mathrm{DMU}_{o}$ relative to the group- $k$ frontier. By using (7) separately for every DMU in the group at every time, all the facets on the group- $k$ frontier can be identified [16]. The term $\theta_{o}^{k}$ determines the technical efficiency relative to the group frontier (DEA-K).

Finally, this paper can obtain a measure of how close the group- $k$ frontier is to the metafrontier. Specifically, the noorientated SBM DEA-MTR for group-k firms is defined as

$$
\operatorname{MTR}_{o}^{k}=\frac{\tau_{o}^{*}}{\theta_{o}^{k *}}, \quad o=1, \ldots, n_{k}, \quad k=1, \ldots, K .
$$

DEA-MTR refers to this measure as the technology gap ratio. However, increases in the DEA-MTR mean decreases in the gap between the group frontier and the metafrontier [24].

\section{Empirical Results}

4.1. Smartphone Function Performance Analysis. First, the performance analysis was conducted using the Consumer Reports evaluations of smartphones for the 2013-2015 period. The evaluation results were converted into numeric scores as described in Section 3.2. Subsequently, the scores for all 
TABLE 5: Annual qualitative analysis of smartphone brands ( $n=200$ smartphone-year observations).

\begin{tabular}{|c|c|c|c|c|c|c|c|c|c|c|c|}
\hline Year & Brand & Q1 & Q2 & Q3 & Q4 & Q5 & Q6 & Q7 & Q8 & Q9 & Q10 \\
\hline 2013 & Apple & 5.00 & 4.00 & 3.14 & 4.86 & 3.00 & 4.00 & 3.00 & 3.29 & 3.86 & 4.86 \\
\hline 2013 & BlackBerry & 3.80 & 4.20 & 3.20 & 4.80 & 2.60 & 3.80 & 3.00 & 2.80 & 2.60 & 4.40 \\
\hline 2013 & HTC & 4.50 & 4.70 & 4.40 & 4.50 & 2.90 & 4.00 & 3.00 & 2.70 & 2.60 & 3.50 \\
\hline 2013 & LG & 4.80 & 4.80 & 4.60 & 4.40 & 2.40 & 3.80 & 3.00 & 2.80 & 2.00 & 4.00 \\
\hline 2013 & Motorola & 4.80 & 4.80 & 4.60 & 3.80 & 3.00 & 4.00 & 3.60 & 3.80 & 2.60 & 3.60 \\
\hline 2013 & Nokia & 4.00 & 5.00 & 5.00 & 5.00 & 3.00 & 4.00 & 3.00 & 2.00 & 3.00 & 3.00 \\
\hline 2013 & Samsung & 4.84 & 4.79 & 4.79 & 4.63 & 2.79 & 4.32 & 3.05 & 3.37 & 2.53 & 3.79 \\
\hline 2013 & Sony & 4.00 & 4.00 & 4.00 & 4.50 & 2.50 & 4.00 & 3.50 & 3.50 & 2.50 & 3.50 \\
\hline \multicolumn{2}{|r|}{ Mean } & 4.47 & 4.54 & 4.22 & 4.56 & 2.77 & 3.99 & 3.14 & 3.03 & 2.71 & 3.83 \\
\hline 2014 & Apple & 5.00 & 4.00 & 4.00 & 5.00 & 3.00 & 4.00 & 3.00 & 4.20 & 4.00 & 5.00 \\
\hline 2014 & BlackBerry & 4.38 & 4.50 & 4.25 & 4.63 & 2.63 & 4.00 & 3.88 & 3.63 & 2.88 & 4.13 \\
\hline 2014 & HTC & 4.82 & 4.91 & 5.00 & 4.91 & 2.64 & 4.00 & 4.09 & 3.18 & 2.73 & 4.00 \\
\hline 2014 & LG & 4.90 & 4.80 & 4.70 & 4.80 & 2.80 & 3.70 & 3.90 & 3.20 & 2.30 & 3.90 \\
\hline 2014 & Motorola & 5.00 & 5.00 & 5.00 & 4.80 & 3.00 & 4.00 & 3.60 & 4.00 & 3.00 & 3.80 \\
\hline 2014 & Nokia & 4.83 & 5.00 & 5.00 & 5.00 & 3.00 & 4.00 & 4.00 & 4.00 & 2.67 & 3.50 \\
\hline 2014 & Samsung & 4.95 & 4.84 & 5.00 & 4.79 & 2.84 & 4.37 & 3.95 & 4.11 & 3.00 & 3.58 \\
\hline 2014 & Sony & 5.00 & 5.00 & 5.00 & 5.00 & 3.00 & 4.00 & 4.00 & 4.00 & 3.00 & 4.00 \\
\hline \multicolumn{2}{|r|}{ Mean } & 4.86 & 4.76 & 4.74 & 4.87 & 2.86 & 4.01 & 3.80 & 3.79 & 2.95 & 3.99 \\
\hline 2015 & Apple & 5.00 & 4.00 & 3.89 & 5.00 & 3.00 & 4.00 & 3.00 & 3.89 & 4.00 & 5.00 \\
\hline 2015 & BlackBerry & 4.00 & 4.43 & 4.00 & 4.57 & 2.71 & 3.86 & 3.86 & 3.57 & 2.86 & 4.00 \\
\hline 2015 & HTC & 4.70 & 4.70 & 4.70 & 4.90 & 2.40 & 3.90 & 3.60 & 2.90 & 3.00 & 3.80 \\
\hline 2015 & LG & 4.73 & 4.87 & 4.67 & 4.20 & 2.87 & 4.07 & 4.27 & 3.33 & 2.87 & 3.47 \\
\hline 2015 & Motorola & 5.00 & 4.33 & 4.83 & 4.17 & 2.83 & 4.17 & 3.83 & 3.00 & 3.00 & 4.17 \\
\hline 2015 & Nokia & 4.57 & 4.29 & 4.43 & 4.71 & 3.00 & 3.71 & 3.29 & 3.29 & 3.00 & 3.43 \\
\hline 2015 & Samsung & 4.67 & 4.71 & 4.76 & 4.62 & 2.81 & 4.14 & 4.24 & 3.62 & 3.38 & 3.52 \\
\hline 2015 & Sony & 4.00 & 5.00 & 5.00 & 5.00 & 3.00 & 4.00 & 4.00 & 4.00 & 4.00 & 4.00 \\
\hline \multicolumn{2}{|r|}{ Mean } & 4.58 & 4.54 & 4.53 & 4.65 & 2.83 & 3.98 & 3.76 & 3.45 & 3.26 & 3.92 \\
\hline
\end{tabular}

Note. Q1 = ease of use, Q2 = messaging, Q3 = Web browsing, Q4 = display quality, Q5 = voice quality, Q6 = phoning, Q7 = battery life, Q8 = camera image quality, Q9 = camera video quality, and Q10 = portability.

models of each brand were aggregated to obtain the annual mean value of each brand (Table 5). Table 5 illustrates each smartphone brand's performance. Apple was either first or equal first for Q1 (ease of use), Q5 (voice quality), Q9 (camera video quality), and Q10 (portability) for all 3 years in the study period. Despite poor performance in 2013, Sony was either first or equal first for Q2 (messaging), Q3 (web browsing), Q4 (display quality), and Q5 (voice quality) in 2014 and 2015. By contrast, BlackBerry was the only brand with poor performance in all 3 years, indicating that BlackBerry smartphones functioned less favorably than other smartphone brands.

Other brands exhibited high performance in some indicators each year, although there was no consistent trend. For example, HTC had the poorest performance among the eight smartphone brands in both 2013 and 2015 but performed well in Q3 (web browsing) and Q7 (battery life) in 2014. Finally, all brands attained scores lower than 3 in Q5 (voice quality), indicating that all smartphone brands should prioritize improving the voice quality of their products. In addition, these smartphone brands exhibited inconsistent results in Q6 (phoning), Q7 (battery life), and Q8 (camera image quality), indicating that these three features are highly competitive in the smartphone market (i.e., they exhibited an inability to maintain an advantage and were likely to require replacement).

In summary, Apple had relatively outstanding performance in all indicators compared with other brands, indicating that other brands should recognize Apple as a benchmark. Although Samsung's flagship models generally had the highest overall scores for each year, Samsung's overall brand performance was more widely dispersed because the company released more smartphone models than any other brands and could not focus on one or two products as Apple did.

4.2. Brand Efficiency. A brand can be defined as efficient if it provides the highest value for money for a set of characteristics [2]. The DEA approach, which is a set of linear programming procedures for measuring the efficiency of a process characterized by multiple inputs and outputs $[22,25]$, can be applied to measure the efficiency of any brand, when the brand is defined as yielding several characteristics for a given expenditure. 
TABLE 6: Smartphone brand decomposition results stratified by brands: summary.

\begin{tabular}{|c|c|c|c|c|c|c|c|c|c|c|c|c|}
\hline \multirow{3}{*}{ Brand } & \multicolumn{12}{|c|}{ Year } \\
\hline & \multicolumn{4}{|c|}{ DEA-MF } & \multicolumn{4}{|c|}{ DEA-K } & \multicolumn{4}{|c|}{ DEA-MTR } \\
\hline & 2013 & 2014 & 2015 & Mean & 2013 & 2014 & 2015 & Mean & 2013 & 2014 & 2015 & Mean \\
\hline Apple & 0.881 & 0.963 & 0.967 & 0.937 & 0.893 & 0.963 & 0.967 & 0.941 & 0.985 & 1.000 & 1.000 & 0.995 \\
\hline BlackBerry & 0.768 & 0.852 & 0.834 & 0.818 & 0.894 & 0.982 & 0.954 & 0.943 & 0.862 & 0.868 & 0.876 & 0.869 \\
\hline HTC & 0.797 & 0.881 & 0.831 & 0.836 & 0.843 & 0.956 & 0.896 & 0.898 & 0.945 & 0.922 & 0.928 & 0.932 \\
\hline LG & 0.780 & 0.853 & 0.865 & 0.833 & 0.823 & 0.902 & 0.939 & 0.888 & 0.948 & 0.946 & 0.923 & 0.939 \\
\hline Motorola & 0.837 & 0.921 & 0.882 & 0.880 & 0.883 & 0.963 & 0.966 & 0.937 & 0.946 & 0.956 & 0.913 & 0.938 \\
\hline Nokia & 0.769 & 0.896 & 0.811 & 0.825 & 0.833 & 0.966 & 0.892 & 0.897 & 0.923 & 0.928 & 0.911 & 0.921 \\
\hline Samsung & 0.834 & 0.927 & 0.898 & 0.886 & 0.840 & 0.937 & 0.898 & 0.892 & 0.993 & 0.990 & 1.000 & 0.994 \\
\hline Sony & 0.788 & 0.930 & 0.952 & 0.890 & 0.833 & 1.000 & 1.000 & 0.944 & 0.947 & 0.930 & 0.952 & 0.943 \\
\hline Mean & 0.807 & 0.903 & 0.880 & & 0.855 & 0.959 & 0.939 & & 0.944 & 0.943 & 0.938 & \\
\hline
\end{tabular}

Note. DEA-MF denotes technical efficiency relative to the metafrontier. DEA-K denotes technical efficiency relative to the group frontiers. DEA-MTR refers to the technology gap ratio (DEA-K/DEA-MF).

After using Consumer Reports data on a group of smartphones to estimate their technical efficiency relative to the metafrontier (DEA-MF), the relative efficiency of smartphones within a group (e.g., brand) was easy to measure. There is considerable interest in measuring the efficiency of smartphones across groups (e.g., comparing the efficiency levels of Apple with those of Samsung). However, such comparisons are meaningful only in special cases where the frontiers for different groups of firms are identical. In general, efficiency levels measured relative to one frontier (e.g., the Apple frontier) cannot be compared with the efficiency levels measured relative to another frontier (e.g., the Samsung frontier).

First, Table 6 shows that smartphone brands had the highest average DEA-MF in 2014, with all brands attaining scores of $\geq 0.8$. This may be attributable to 2014 being the peak smartphone growth period and the relatively high number of models released in that year. The technology boom led to relatively high efficiency (i.e., the quality-price relationship), which favored consumers. In 2015, the overall brand efficiency exhibited a downward trend, indicating a wide technology gap between brands. Table 6 shows that most smartphone brands followed the general trend by peaking in 2014. In 2015, four brands exhibited a downward trend, whereas the other four exhibited an upward trend. Apple, Sony, and Samsung exhibited the highest brand efficiency among the eight surveyed brands.

Second, this study further examined the synergy between telecommunications operators and smartphone manufacturers. The four major telecommunications operators were AT\&T, Sprint, T-Mobile, and Verizon. Some operators did not carry certain smartphone brands (these are marked with an "X" in Table 7). For example, Sprint did not carry Nokia or Sony smartphones, and T-Mobile did not carry Motorola smartphones. Table 7 shows that Apple exhibited the highest synergy with telecommunications operators, followed by Samsung. These two brands also exhibited the most efficient mobile operating systems (iOS and Android, resp.) and had the smallest technology gap. Platform preferences may influence consumers' brand choices [13]. Apple's high efficiency may be attributable to the relatively high subsidy paid to operators and high customer loyalty as the forerunner of the smartphone market. Despite having a wide range of available models and generally good performance in various test results, Samsung's overall efficiency was offset by their inefficient low-end models, and the company still could not overtake Apple in brand efficiency. Although 2013 data were not available for Sony smartphones, the Japanese conglomerate caught up with the other brands in brand efficiency in 2014 and 2015. After being acquired by Lenovo, Motorola returned to China's market and subsequently simplified their product strategy. They annually released only one or two models for each price level, effectively improving their brand efficiency. However, despite these efforts, Apple maintained its dominance in the smartphone market. These results show that brand image is a crucial factor of brand efficiency.

To determine whether efficiency differs significantly among the telecommunication operators and brands, this study adopted the Kruskal-Wallis test. At the significance level of 5\%, we observed no significant difference in the performance of telecommunication operators' efficiency among the regions. However, a significant difference was observed in the performance of the economic efficiency among the brands. Table 7 indicates that variation in the telecommunication operators did not significantly affect their brand efficiency, and the brands themselves were the crucial factors determining their efficiency. Details are shown in Table 7.

4.3. Technology Gap Analysis. To understand the technology gap between different brand smartphone frontiers and all brand smartphone frontier, the metafrontier concept was first-time employed to measure the technology gap of various smartphone manufacturers in this study. The DEA-MTR is the most crucial indicator for this evaluation. An increasing DEA-MTR leads to a reduction in the technology gap between the global frontier and group frontier.

Based on the aforementioned definition, a higher value indicates a lower DEA-MTR. Table 6 shows that the average DEA-MTR had declined from 0.944 in 2013 to 0.938 in 2015. Therefore, in a competitive market, the strongest brands 
TABLE 7: Average DEA-MF of telecommunication operators in 2013-2015.

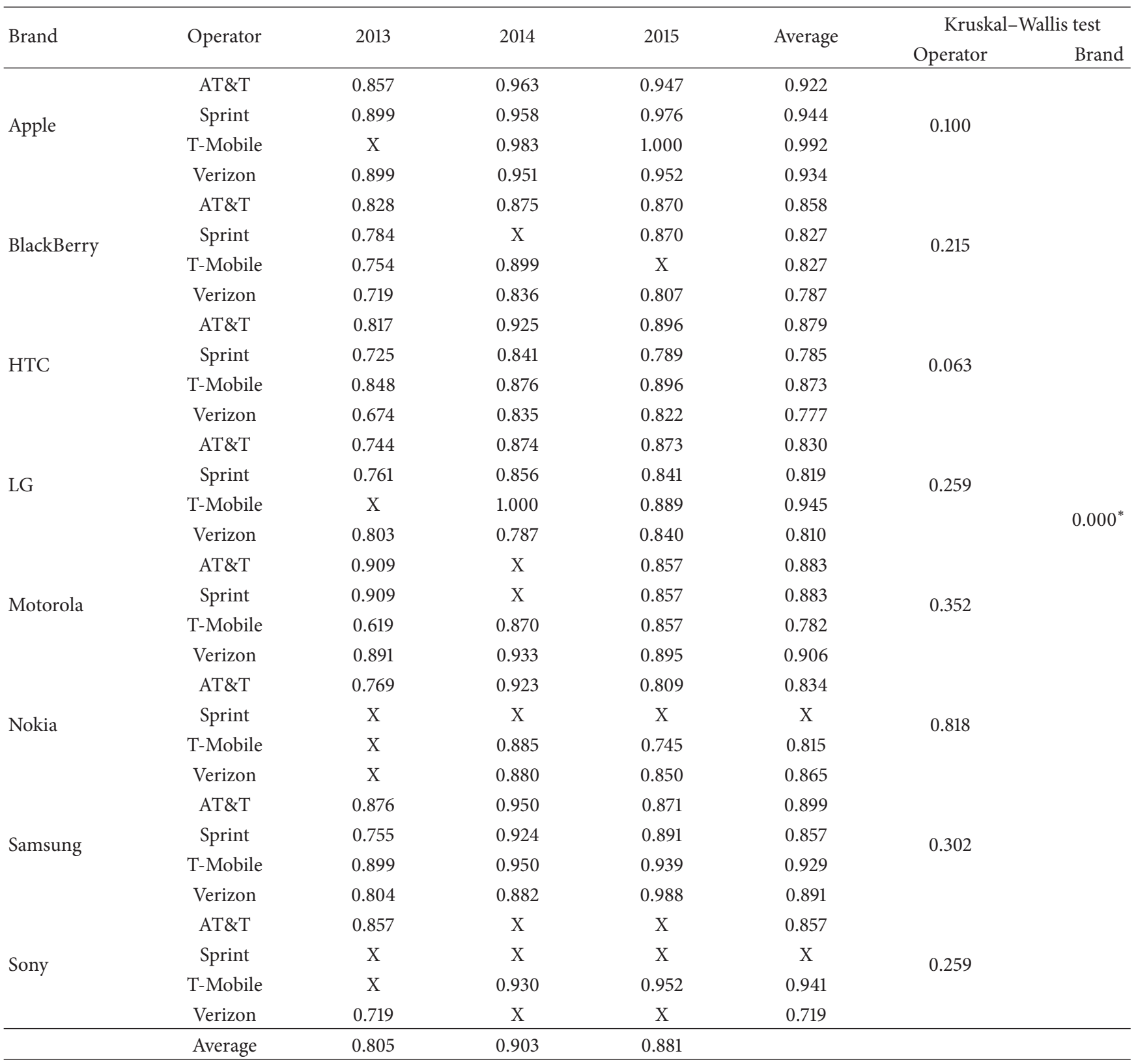

Note 1. X indicates no partnership between the brand and the operator; ${ }^{*} p<0.05$; Note $2 . \eta_{0}$ is the technical efficiency relative to the metafrontier (DEA-MF).

remain strong and the weakest brands remain weak; Apple is an example of a strongest brand. The results in Section 4.1 show that Apple maintains consistent quality and retains its competitive advantages. In addition, Motorola and Sony exhibited greater annual variation in DEA-MTR than the other brands did, resulting in considerable year-by-year fluctuations. Although Samsung trailed Apple by a $0.1 \%$ in average DEA-MTR, both Samsung and Apple reached 1.000 in 2015, indicating that Samsung was catching up to Apple. Furthermore, BlackBerry exhibited a significant gap in DEA-MTR from other brands, with a room-for-improvement rating of $13.1 \%$.

\section{Discussion and Conclusion}

To understand whether smartphone brands affect market efficiency, this study analyzed a total of 200 observations of eight smartphone brands from 2013 to 2015. The main objective was to compare market efficiency according to smartphone brand and understand the variance by calculating the DEA-MTR of each group through the metafrontier concept. Recommendations are proposed for the alleviation of DEA-MTR and improvement for inefficient brands.

The study results yielded three findings. First, from the brand efficiency perspective, each year featured a different 
market leader, and most brands exhibited a consistent trend. However, some brands departed from the trend line, potentially causing variance in the data for a particular year. For example, Nokia diverged from the general trend because of its strategic policy. Second, from the DEA-MTR perspective, LG, Motorola, and Nokia exhibited a trend of annual changes different from other brands. Finally, for all four major US telecommunications operators, Apple was the most efficient brand. The second-most efficient brand was Samsung for AT\&T and Sprint, Sony for T-Mobile, and Motorola for Verizon.

Samsung is an interesting case. The average DEA-MF score shows that Samsung ranked third among brands. This result proved that product diversified strategy is very successful. Samsung's average DEA-K score ranked seventh among brands, which shows that the efficiency between functions and price in different model has a large gap. This indicates that Samsung adopted an effective product segmentation strategy. The average DEA-MTR score shows that Samsung ranked second. This points out that Samsung has an excellent level of production technology, second only to Apple. Overall, Samsung's mobile phone department has an extremely good competitiveness.

Several suggestions are proposed for smartphone consumers and manufacturers. First, consumers may refer to the annual change in brand efficiency when they purchase smartphones and select efficient products according to future trends in brand efficiency. Second, the concepts of benchmark enterprises and annual changes in brand efficiency may serve as reference for technological improvement for smartphone manufacturers. The DEA-MTR indicator also identifies the variation of overall technology between brands by analyzing whether brands are annually trending toward or away from the general population. Trending toward the general population indicates gradual technological improvement annually, whereas trending away from the general population indicates gradual technological decline. Smartphone manufacturers with obsolete technologies may eventually be eliminated from the market.

To overcome the data collection limitations encountered in this study, recommendations are proposed for future research. First, the data obtained from Consumer Reports contained market information for the US market only; future studies should consider using data from other countries or regions. Second, this study adapted the inputs and outputs from Consumer Reports as the only variables; future studies are recommended to consider using other variables. Third, the data collected for this study ranked the products in an ordinal scale; future studies may wish to adopt a nominal scale to measure the outputs.

Finally, the brands selected in this study were the top brands in market share in each year; other brands were not considered. As mentioned in Section 1, a total of 1.293 billion smartphones were shipped globally in 2015, and 539 million of those smartphones were made by Chinese manufacturers. Although Samsung and Apple still dominate the smartphone market, a Chinese company is placed seventh in market share. Consumer Reports included Motorola, which was recently acquired by Lenovo, but other Chinese smartphone brands should also be accounted for in future research.

\section{Conflicts of Interest}

The authors declare no conflicts of interest regarding the publication of this paper.

\section{References}

[1] M. Pandey and N. Nakra, "Consumer preference towards smartphone brands, with special reference to android operating system," IUP Journal of Marketing Management, vol. 13, no. 4, pp. 7-22, 2014.

[2] W. A. Kamakura, B. T. Ratchford, and J. Agrawal, "Measuring market efficiency and welfare loss," Journal of Consumer Research, vol. 15, no. 3, p. 289, 1988.

[3] K. Lancaster, Consumer Demand: A New Approach, Columbia University Press, New York, Ny, USA, 1971.

[4] S. Rosen, "Hedonic prices and implicit markets: product differentiation in pure competition," Journal of Political Economy, vol. 82, no. 1, pp. 34-55, 1974.

[5] C. Liu and H. Liang, "The deep impression of smartphone brand on the customers' decision making," Procedia - Social and Behavioral Sciences, vol. 109, pp. 338-343, 2014.

[6] D. M. Rousseau, S. B. Sitkin, R. S. Burt, and C. Camerer, "Not so different after all: A cross-discipline view of trust," Academy of Management Review, vol. 23, no. 3, pp. 393-404, 1998.

[7] A. M. Spence, Market Signaling: Informational Transfer in Hiring and Related Screening Processes, Harvard University Press, 1974.

[8] A. Charnes, W. W. Cooper, and E. Rhodes, "Measuring the efficiency of decision making units," European Journal of Operational Research, vol. 2, no. 6, pp. 429-444, 1978.

[9] G. J. Tellis and B. Wernerfelt, "Competitive price and quality under asymmetric information," Marketing Science, vol. 6, no. 3, pp. 240-253, 1987.

[10] A. Chaudhuri and M. B. Holbrook, "The chain of effects from brand trust and brand affect to brand performance: the role of brand loyalty," Journal of Marketing, vol. 65, no. 2, pp. 81-93, 2001.

[11] P. Jiang and S. K. Balasubramanian, "An empirical comparison of market efficiency: Electronic marketplaces vs. traditional retail formats," Electronic Commerce Research and Applications, vol. 13, no. 2, pp. 98-109, 2014.

[12] C. Lee, D. Lee, and J. Hwang, "Platform openness and the productivity of content providers: A meta-frontier analysis," Telecommunications Policy, vol. 39, no. 7, pp. 553-562, 2015.

[13] C.-H. Yeh, Y.-S. Wang, and K. Yieh, "Predicting smartphone brand loyalty: Consumer value and consumer-brand identification perspectives," International Journal of Information Management, vol. 36, no. 3, pp. 245-257, 2016.

[14] B. S. Chakravarthy, "Measuring strategic performance," Strategic Management Journal, vol. 7, no. 5, pp. 437-458, 1986.

[15] G. E. Battese and D. P. Rao, "Technology gap, efficiency, and a stochastic metafrontier function," International Journal of Business and Economics, vol. 1, no. 2, pp. 87-93, 2002.

[16] C. J. O’Donnell, D. S. P. Rao, and G. E. Battese, "Metafrontier frameworks for the study of firm-level efficiencies and technology ratios," Empirical Economics, vol. 34, no. 2, pp. 231-255, 2008 . 
[17] W. W. Cooper, L. M. Seiford, and J. Zhu, "A unified additive model approach for evaluating inefficiency and congestion with associated measures in DEA," Socio-Economic Planning Sciences, vol. 34, no. 1, pp. 1-25, 2000.

[18] A. Charnes, W. W. Cooper, B. Golany, L. Seiford, and J. Stutz, "Foundations of data envelopment analysis for ParetoKoopmans efficient empirical production functions," Journal of Econometrics, vol. 30, no. 1-2, pp. 91-107, 1985.

[19] R. R. Russell, "Measures of technical efficiency," Journal of Economic Theory, vol. 35, no. 1, pp. 109-126, 1985.

[20] K. Aida, W. W. Cooper, J. T. Pastor, and T. Sueyoshi, "Evaluating water supply services in Japan with RAM: A range-adjusted measure of inefficiency," Omega, vol. 26, no. 2, pp. 207-232, 1998.

[21] K. Tone, "A slacks-based measure of efficiency in data envelopment analysis," European Journal of Operational Research, vol. 130, no. 3, pp. 498-509, 2001.

[22] R. D. Banker, A. Charnes, and W. W. Cooper, "Some models for estimating technical and scale efficiencies in data envelopment analysis," Management Science, vol. 30, no. 9, pp. 1078-1092, 1984.

[23] A. Charnes and W. W. Cooper, "Programming with linear fractional functionals," Naval Research Logistics Quarterly, vol. 9, pp. 181-186, 1962.

[24] G. E. Battese, D. S. P. Rao, and C. J. O’Donnell, "A metafrontier production function for estimation of technical efficiencies and technology gaps for firms operating under different technologies," Journal of Productivity Analysis, vol. 21, no. 1, pp. 91-103, 2004.

[25] R. Färe and S. Grosskopf, "Measuring output efficiency," European Journal of Operational Research, vol. 13, no. 2, pp. 173-179, 1983. 


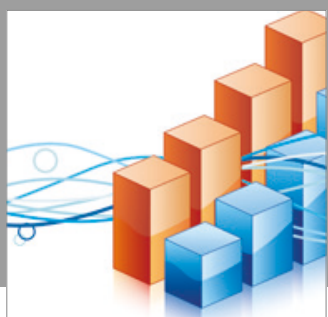

Advances in

Operations Research

vatersals

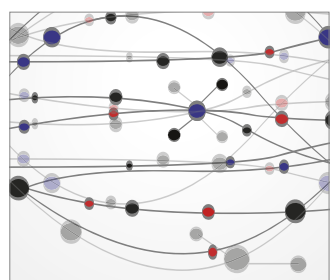

\section{The Scientific} World Journal
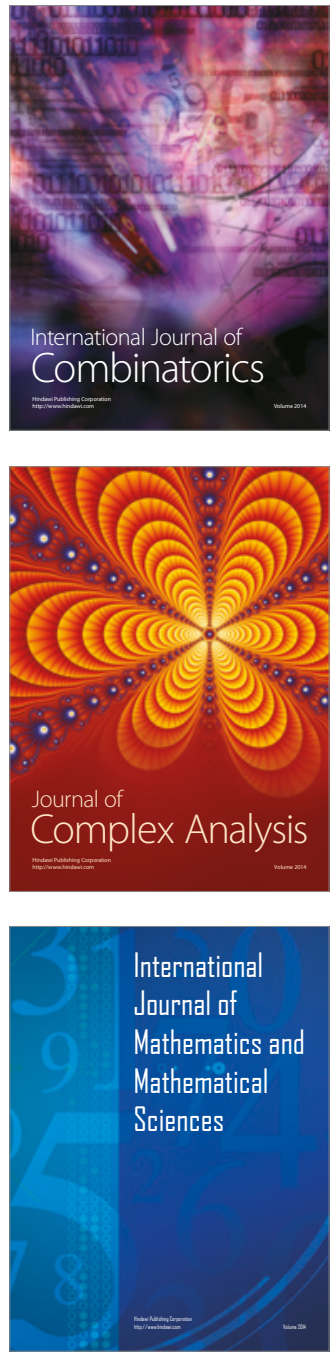
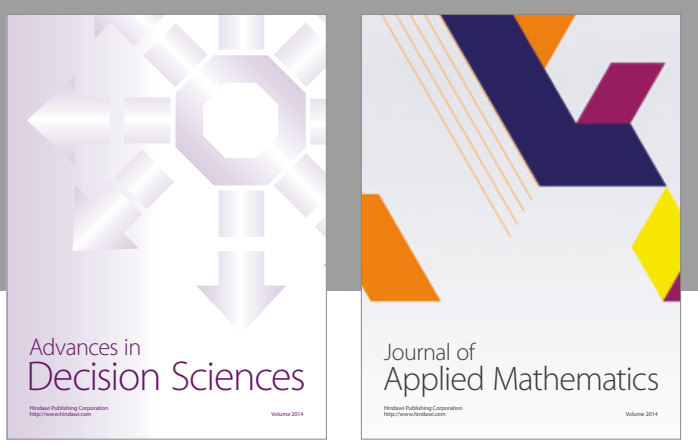

Algebra

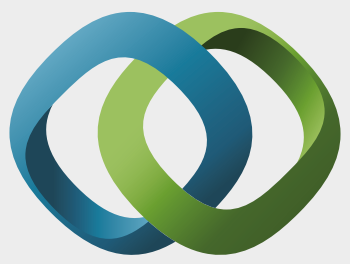

\section{Hindawi}

Submit your manuscripts at

https://www.hindawi.com
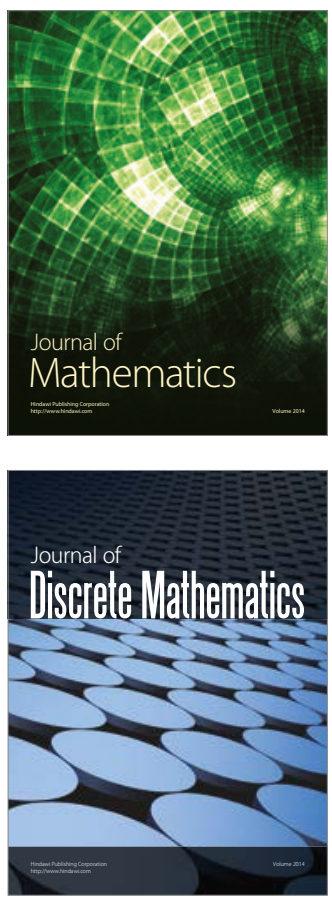

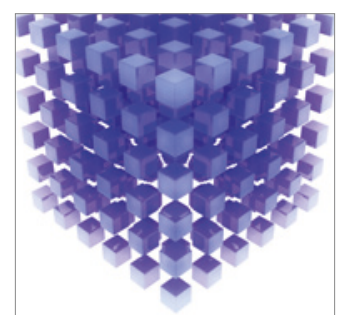

Mathematical Problems in Engineering
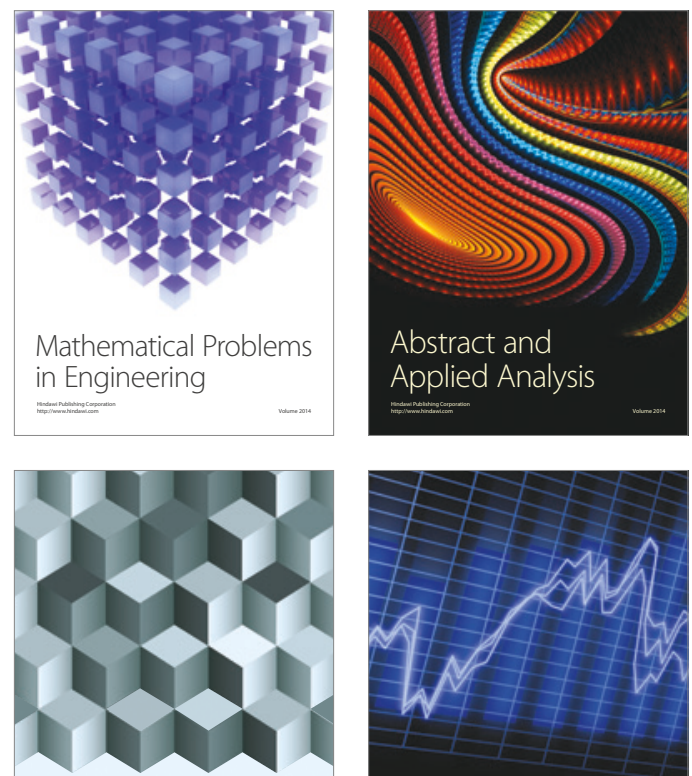

Journal of

Function Spaces

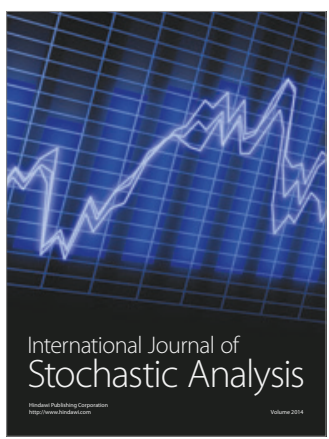

Probability and Statistics
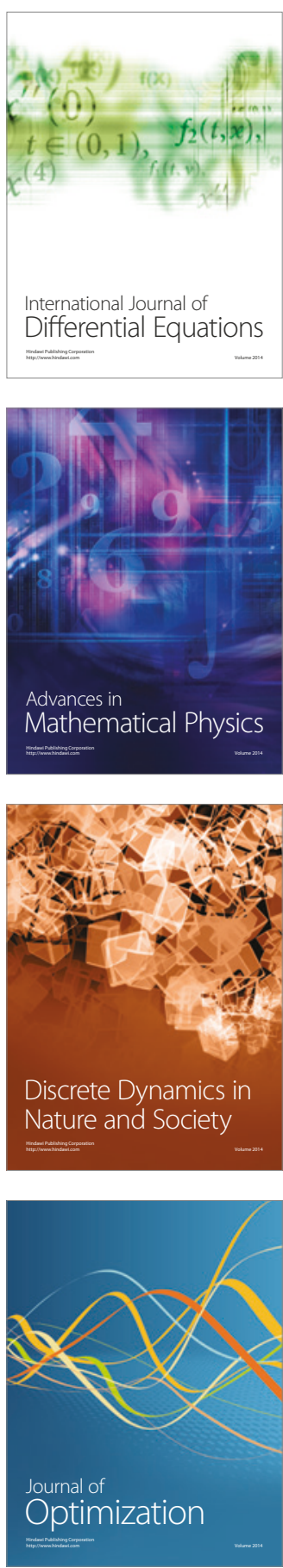